\title{
Social Media in the Workplace: Influence on Employee Agility and Innovative Behavior
}

\author{
Hillol Bala, Kelley School of Business, Indiana University, hbala@indiana.edu \\ Anne P. Massey, Wisconsin School of Business, University of Wisconsin-Madison, apmassey@wisc.edu \\ Seyoung Seol, Kelley School of Business, Indiana University, seols@indiana.edu
}

\begin{abstract}
Despite the increasing adoption of enterprise social media (ESM), little research has examined the link between ESM use and job outcomes. We examine this link, highlighting the role of agility at an individual level. We adopt two measures of use - deep structure use (view, create, and respond) and cognitive absorption use. We develop and operationalize work agility and communication agility as primary benefits of ESM use, which are hypothesized to affect employees' innovative behavior outcomes. Using two waves of surveys from a Fortune 500 company, we found that create and respond were significant for work agility, while create and view were significant for communication agility. Cognitive absorption use influences both work and communication agility. Counter-intuitively, we found a negative effect of communication agility on innovative behavior, while work agility was positive as expected. This research sheds light on the underlying influence mechanism of ESM use from the dual perspective of system use.
\end{abstract}

\section{Introduction}

Social media platforms have changed the way individuals communicate. Evidence suggests that organizational implementation of such platforms is increasing. For example, according to Eurostat [18], the official statistical office of EU, the number of companies that have adopted social media had increased from $28 \%$ in 2013 to $36 \%$ in 2015 . In 2015, $40 \%$ of businesses have implemented social media for internal purposes such as fostering knowledge sharing within an enterprise [17]. Although there has been much focus on public social media platforms (e.g., Facebook, Twitter, and LinkedIn) in both practitioners' literature and academic research, there has been limited research on enterprise social media (ESM) platforms. Specifically, despite the increasing adoption of ESM in business, there has been no research examining the fundamental link between employees' ESM use and their job outcomes.

In this paper, we suggest that implementation of ESM will fundamentally change the way employees work. We introduce the notion of agility at an individual level and examine how employees' ESM use affects employees' agility in the workplace. Agility is not a new concept and has been studied by many academic disciplines. However, agility at an individual level has received scarce attention. For instance, we could not find a single research paper studying agility at an individual level in leading information systems (IS) journals. Nonetheless, prior literature on organizational agility has consistently noted that employee agility is a crucial component of organizational agility. For example, Chonko and Jones [9] note that organizational agility reflects the people who comprise it working together. Earlier studies also suggest that learning activities at the employee/individual level are critical for an enterprise to be agile [7][10] [34][38]. In the context of IS, researchers consistently argue that employees' agility is an important component of organizational agility [19][36]). Tallon and Pinsonneault [33] further posited that IT use could improve employees' capability, which contributes later to organizational agility.

Given all this, we argue that agility applies to an individual level as well. Due to its salience in composing organizational agility, we can keep the definition of organizational agility and apply it to the individual level. Yusuf et al. [40] defined organizational agility as the ability to exploit competitive bases such as speed, flexibility, innovation proactivity, quality, and profitability by reconfiguring resources and best practices in a knowledge-rich environment to adjust to a fast-changing market environment. We can replace organizational agility with individual agility without harming the overall meaning of the original definition. We will introduce the formal definition of employee agility in the next section.

The objective of this study is to understand the impact of employees' ESM use on their agility in the workplace, which in turn contributes to job outcomes. We conceptualize two constructs reflecting employee agility - work agility and communication agility. Drawing from the prior argument that speed and flexibility are at the heart of the agility [7], we define work agility as employees' ability to find work-related resources (e.g., information, colleagues' opinions, an internal expert, etc.) necessary to resolve an issue promptly. We define communication agility as 
employees' ability to communicate with coworkers speedily and optimize communication load to manage their time efficiently.

We also adopt two rich measures of system use deep structure use and cognitive absorption use. Deep structure use represents the extent to which ESM features related to an individual's tasks are used [16]. Cognitive absorption use reflects the extent to which a user is immersed while using ESM [2]. The adoption of rich measures of system use is essential because lean measures (e.g., duration, frequency, and intensity) have limited ability to explain the vibrant spectrum of individuals' system use [8]. That is, they are a mere representation of system use without the consideration of components of individuals' system use behavior. Moreover, extending [8], we argue that deep structure use and cognitive absorption use must be considered singly due to the duality of system use in our context.

\section{Background}

In the following, we first review and discuss previous studies on ESM to grasp the current level of understanding. We then discuss two rich measures of system use. Finally, we introduce two dimensions of employee agility in the workplace, which we later propose as central mediators driving job outcomes.

\subsection{Prior studies on enterprise social media}

From the online archives of major IS journals - MIS Quarterly, Information System Research, Journal of Management Information Systems, and Management Science, we reviewed relevant research with the search term 'enterprise social media.' Despite the increasing adoption of ESM, we found only five relevant studies.

Wu [37] examined if ESM can induce a change in network positions and whether this change affects employees' work outcomes in the context of a large IT firm. She found that, contrary to the previous belief that network positions are difficult to alter, ESM use can induce a change in a network structure. Also, she identified that individuals could derive economic benefits from the network to which they belong. Beck et al. [6] investigated antecedents of knowledge exchange in ESM by proposing a multilevel model of the characteristics of knowledge seekers, knowledge contributors, and the relationship between them. They found that knowledge seekers' characteristics and relational factors are crucial in driving knowledge exchanges in ESM in contrast to the previous finding that knowledge contributors primarily drive effective knowledge exchange. Leonardi [24] explored how the increasing visibility of communication from ESM use might shape knowledge sharing in organizations. He conducted interviews and content analysis in a large financial services firm and found that seeing the contents of others' messages help third-party observers make inferences about coworkers' knowledge. He also observed that enhanced meta-knowledge (i.e., knowledge of 'who knows what' and 'who knows whom') can lead to more innovative products and services and less knowledge duplication. Leonardi [25] further analyzed the role of ESM in increasing the accuracy of people's meta-knowledge at work. He found that ESM enabled users to become aware of communications among their coworkers and make inferences about what and whom those coworkers know based on the contents of the messages exchanged. Lastly, Huang et al. [22] developed a dynamic structural framework to analyze the content creation and consumption behavior in ESM. They found that, despite higher utility from work-related ESM use, leisurerelated ESM use has positive spillovers for work-related ESM use, suggesting that a policy of abolishing leisurerelated content creation can have adverse consequences.

Although these studies provide valuable insights, a fundamental question has not yet been explored - Does employees' ESM use influence job outcomes? And, a related question - What are the main drivers bridging use and job outcomes? Before presenting our research model, we introduce two salient constructs - rich measures of system use and employee agility.

\subsection{Operationalization of system use}

System use measures widely adopted in IS research in the past include frequency, duration, and use intensity. However, Burton-Jones and Straub [8] criticized those lean measures by arguing that they are incapable of capturing the vibrant spectrum in of individuals' use. They proposed two rich measures cognitive absorption use and deep structure use. Cognitive absorption refers to the extent to which a user is absorbed when using the system [2]. Deep structure use is defined as the extent to which system features that relate to the core aspects of the task are used [16]. Burton-Jones and Straub [8] empirically showed that the relationship between individuals' system use and task performance could be better explained by these rich measures than lean measures.

It is essential to be cautious against lean measures of system use. Lean measures can increase errors of inclusion and omission because they are limited in reflecting what constitutes usage and what parts of usage the researcher intends to measure [8]. Due to this critical restriction, lean measures failed to explain how the use of an organizational IS induces work outcomes. In contrast, rich measures provide meaningful insights to examine the relationship. As such, we adopt the two rich measures of system use to measure the level of employees' ESM use in the workplace. 


\subsection{Employee agility in the workplace}

Employee agility has not gained much attention in the literature, leading to no clear agreement on its definition. Qin and Nembhard [29] defined workforce agility as the ability of workers to respond strategically to uncertainty with an emphasis of its greater salience in enterprises which rely heavily on the workforce to transfer cutting-edge technologies into products. Muduli [26] conceptualized an agile workforce as well-trained and flexible, adapting quickly and easily to new opportunities and market circumstances. However, those two definitions narrow the scope of agility with a heavy focus on employees' capability of responding to uncertainty and new opportunities. Although the notions of speed and flexibility are at the heart of the agility concept [7], the conceptualization of employee agility in previous studies fails to provide details on what constitutes employee agility.

Drawing from Yusuf et al. [40], we re-conceptualize employee agility as the capability to exploit competitive bases (i.e., speed, flexibility, innovation proactivity, quality, and profitability) through the integration of reconfigurable resources and best practices in order to efficiently react to a fast-changing environment. We treat employee agility as an individual state - a temporary behavior or feeling that depends on a person's situation and time. It is not a trait - stable characteristics. For example, an employee who has high openness and extraversion (two of the big five personality traits) may not necessarily be agile in the workplace. Being agile at work is more relevant to noticing, learning, and responding to a changing environment and surrounding resources at a work situation. Thus, organizational effort aiming to facilitate interaction and knowledge sharing across employees such as ESM implementation will improve their agility.

Previous studies on agility across business fields have suggested that employee agility is a crucial component of organizational agility. Chonko and Jones [9] suggest that organizational agility results from the people who comprise it working together in ways that benefit the individual, the organization, and their customers. Also, prior research has consistently argued that learning at the individual level is necessary for an agile enterprise [10][34][39]. Hopp et al. [21] maintained that firms could achieve greater flexibility by attaining greater employee agility using cross-trained workers who can shift their capacity to where needed.

Although IS has mainly focused on organizational agility, many researchers suggest that organizational agility can be accomplished through agile employees. Fink and Neumann [19] highlighted the importance of the agility of IS personnel for superior IT infrastructure and greater organizational agility. Similarly, Weill et al.
[36] stressed that employees' agility with regard to change is crucial to organizational agility. Tallon and Pinsonneault [33] argued that organizational agility can be promoted by employees' capability to identify new uses for existing IT resources or how IT and non-IT resources can be combined in new and innovative ways.

In sum, prior research suggests that organizations can be agile if individual employees are agile. As some previous studies implied, we believe that the use of IT can promote employee agility by fostering knowledge exchange and collaboration. With superior features over existing collaboration tools, ESM use will encourage employee agility further leading to better performance contributing to organizational agility ultimately. In the next section, we discuss the detailed mechanism on how ESM use can induce greater employee agility.

\section{Research model and hypotheses}

Figure 1 presents our research model. The model posits that the two rich measures of ESM use at $T_{1}$ will influence employee work and communication agility at $T_{2}$. In turn, the two agility constructs will impact innovative behavior.

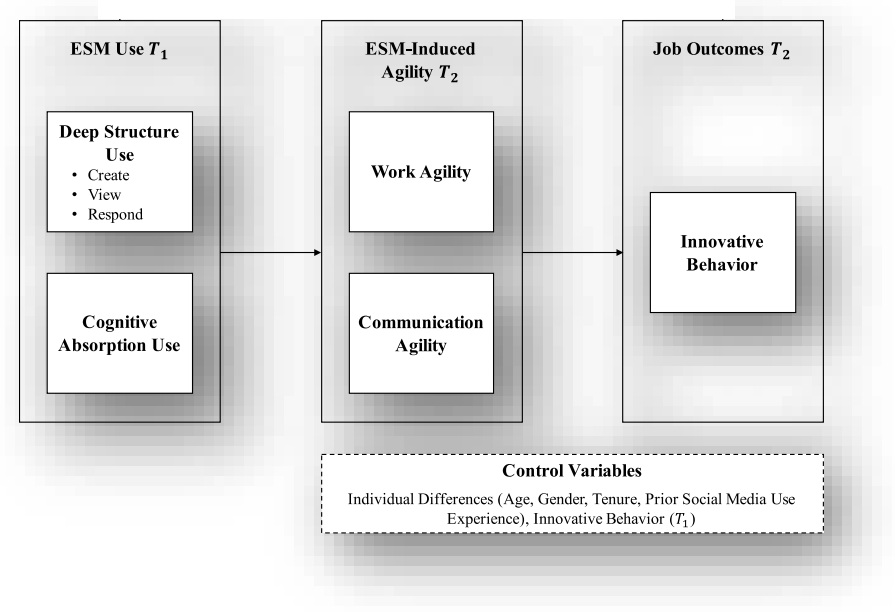

Figure 1. Research model

As noted earlier, there are two rich dimensions of system use: deep structure use and cognitive absorption use. Before proceeding, we offer the rationale on why it is essential to consider deep structure use and cognitive absorption use separately. Compared to other organizational IT, ESM comes with a lot of features that are accessible and permissible to employees to use. A typical ESM software package provides analyticsembedded online communities as well as profiles with files, blogs, wikis, document co-editing, forums, activities, and meetings. Also, the decision to use ESM is voluntary in many real cases. Therefore, some employees may choose to use a lot of these features (i.e., 
deep structure use), while other employees may want to focus on a limited set or get absorbed deeply with a set of features (i.e., cognitive absorption use). Some employees may do both. So, the duality of system use comes to play here. In this regard, we expect that deep structure use and cognitive absorption use will play an important role respectively.

\subsection{Deep structure use and work agility}

Following the central notion of speed and flexibility in the definition of agility, we define work agility as employees' ability to find work resources such as information, colleagues' opinions, and an internal expert necessary to resolve a confronting issue promptly. For deep structure use, we consider create, view, and respond as its sub-dimensions as they are the most fundamental actions taken by users on any social media platforms including both ESM and public social media (e.g., Facebook). Note that the three types of feature use are purposeful actions respectively different from lean measures (e.g., frequency, duration, and intensity) which do not reflect any qualitative meaning.

View is the action of exploring and reading posts on ESM. It is the most basic function since it does not require active engagement such as create and respond. We argue that view contributes to work agility relying on two mechanisms: social learning theory and the theory of communication visibility. First, social learning theory has suggested that most human behavior is learned observationally [5]. That is, one forms an idea of how new behaviors are performed by observing others, and on later occasions, this coded information serves as a guide for action. ESM is an ideal setting to watch and learn from others compared to other existing collaboration tools. This is because it provides a detailed timeline of communication, which often has a format like Wall or News Feed on Facebook. The provision of communication history enables employees to quickly catch up by scrolling without checking multiple sources such as emails and chat logs separately. Due to its relative ease in tracking internal records, employees can get a better sense of how a problem is solved as well as who solved the problem. Second, prior research suggested that employees can still learn about internal resource network even when employees do not interact with someone directly on ESM. According to the theory of communication visibility [25], being able to observe the content of messages people exchange with one another and the directionality of those words are reliable indicators for third-party observers to improve their meta-knowledge on 'who knows whom' and 'who knows what.' While employees look at others' communication, they can update their meta-knowledge. Finding an appropriate person is often challenging. Even with an expert search module installed in an enterprise portal, the database requires a lot of effort to maintain. So, the database is often neither up-to-date nor complete. In contrast, ESM can tell employees who are an expert in real time. Recalling that work agility is the speed of finding work resources, the higher level of meta-knowledge is expected to improve work agility.

Create is the action of writing a post on ESM. Employees can directly ask for help to other coworkers by creating a post. ESM offers an open space where employees can reach out someone who they have never met casually. Accordingly, a created post can benefit from expanding digitized knowledge reach, which is defined as the comprehensiveness and accessibility of codified knowledge in a firm's knowledge base and the interconnected networks and systems that enhance interactions among individuals for knowledge sharing and transfer [30]. Thanks to the extensive reachability of ESM, employees can find someone who has a piece of knowledge and experience related to their tasks on time.

Respond is the action of replying to others' posts. Employees can increase work agility for future events by responding to others' posts on ESM. Providing help to others by responding to their posts promotes a reciprocal relationship, which refers to a pattern of mutually contingent exchange of gratifications [20]. In the workplace, reciprocal relationship prevails because a company is a unit consisting of economic benefit seekers. There have been a group of people whose reciprocity is active in any workplace. Depending on the characteristics of employees, they might not belong to any of it. In this regard, ESM offers a new way to develop reciprocal relationships by a simple action responding to a post as a help. The increase of the pool of potential helpers will expedite future knowledge seeking process. Stated formally:

H1. Deep structure use ((a) view, (b) create, and (c) respond) positively affects work agility.

\subsection{Cognitive adsorption use and work agility}

We expect that cognitive absorption use positively affects work agility. We provide a fundamental rationale by adopting the notion of focused immersion, which suggests that all of the attentional resources of an individual are focused on the particular task while reducing the level of the cognitive burden associated with others [2]. It is noteworthy that employees learn on ESM by reading primarily. Prior research indicated that attention is vital to an accuracy level of learning when an individual is learning through reading [23]. Also, scholars of neuroscience noted that visual attention could improve behavioral performance by observers to focus on the critical information in a complex scene through the increased firing rates of cortical sensory neurons [11]. This evidence is particularly useful in the 
context of ESM because an employees' Wall may look messy due to a large volume of posts. In this regard, focused attention while employees are in cognitive absorption use will result in high performance in obtaining information through ESM. They will filter out unnecessary information irrelevant to a topic in their cognitive processing. Thus, we expect that employees with the high level of cognitive absorption use are more likely to handle a larger volume of task-related information than those who are not. Stated formally:

H2. Cognitive absorption use positively affects work agility.

\subsection{Deep structure use and communication agility}

We define communication agility as employees' ability to communicate with coworkers quickly and optimize communication load to manage their time efficiently. According to Agarwal et al. [1] of Deloitte Insights, 7 out of 10 survey organizations rated the need to simplify work as an essential problem. As one of the therapeutic options, they suggested that organizations can recover employee engagement and higher work quality by reducing the number of emails, meetings, and conference calls. We expect that two sub-dimensions (i.e., view and create) of deep structure use positively affects communication agility, which will reduce the current high level of communication burden.

First, by observing (viewing) others' behavior on ESM, one can understand a nature or culture of an individual, a group, and a whole organization better. According to prior research, even in the same organization, the characteristics of each individual and a group of people are known to be different to some extent. This is not surprising since each has different task variety, a span of control, sociopolitical support, and work climate [32]. It is noteworthy that the difference between an employee and a focal individual (or group) requires the employee behave differently for higher efficiency and effectiveness of communication. As Nahapiet and Ghoshal [27] described in social capital theory, a mutual common background such as shared language and codes is beneficial in social exchange in the workplace. Since employees should face different people related to their tasks, the prior knowledge on their characteristics is likely to enable them to communicate better. If a person is sent to another team or group, the person with a previous understanding of those people will be able to adapt faster and interact with them better.

In a virtual setting such as ESM, media richness theory posits that individuals perform better by matching media characteristics to the needs of processing tasks [13]. Although ESM provides superior functions over existing collaboration tools, communication still occurs electronically. Such communication is generally considered leaner (and thus less efficient and effective) than offline contact due to the limited use of non-verbal cues such as voice inflection, sighs, gestures, and touch [13]. Thus, Dennis et al. [14] noted that the ability of media to support synchronicity, a shared pattern of coordinated behavior among individuals who work together, is essential. As stated earlier, the prior understanding of other colleagues by viewing and updating their metaknowledge is, hence, expected to further supplement the lack of synchronicity of ESM compared to face-to-face. In this regard, we argue that an employee with a higher level of viewing activities on ESM is likely to have better communication capability, which contributes to the expedition of problem-solving within ESM before a need of calling for an offline meeting arises.

Next, employees can try to solve an issue by creating a post asking for help. Creating a post is more active approach than limiting activity to viewing. First, an employee can use ESM to update his or her work status to others. The routine of sharing work status is likely to contribute to the reduction of rising of a significant issue since it can increase the chance of finding and solving a problem in advance. Also, other working members will have a better understanding of the work of the employee before they initiate a talk, further promoting an effective communication. Second, an employee can look for an expert who can help him or her by creating a post. If a trial is successful, this is an efficient way to solve an issue, eliminating the reason for working members to get together. For example, after a question is answered with the help of an internal expert, an employee can announce his or her success to other working members. Depending on subsequent discussion, they may not need to move on to offline meetings especially when an issue is not of great importance. Getting appropriate and immediate help contributes to preventing any group meetings or other communication activities to solve a problem, which can be time-consuming.

To summarize, both view and create are likely to improve the efficiency of communication. The effects are expected to be more salient when employees are overwhelmed by offline meetings for multiple issues of small or medium importance. Note that we did not consider respond here. We basically view respond as an action of virtuous attitude. If the post to which an employee responds is not directly relevant to the communication that the employee handles, the action of responding to the post will simply increase communication burden. We also believe communication agility is a more time-urgent capability and differs from work agility. Since the transition from online communication to offline happens in a relatively short term, the prior reciprocity-based argument seems not to 
work here. We expect that respond does not contribute to the reduction of offline meetings because it is highly questionable when a responder can get a return from the person. Although it will eventually contribute to better work agility as discussed earlier, thus, we argue that the effect will not be significant for reducing not only current communication burden but also an emerging need for face-to-face communication. Stated formally:

H3. Deep structure use ((a) view and (b) create) positively affects communication agility.

\subsection{Cognitive absorption use and communication agility}

Prior research suggested amplified curiosity as a dimension of cognitive absorption use [2]. When employee curiosity is amplified as a result of cognitive absorption, they exhibit higher excitement about available possibilities [35]. Such enthusiasm contributes to reducing the perceived cognitive burden associated with the interaction [2]. Accordingly, with the help of the lowered cognitive load, employees in cognitive absorption use are more likely to participate in the communication on ESM with their working colleagues more actively. Prior research showed that members' active participation facilitates knowledge sharing in virtual knowledge-sharing communities of practice like ESM [3]. That is, an employee in cognitive absorption use are more likely to engage in more fruitful knowledge sharing with working colleagues on ESM. As a result, the higher efficiency of communication with the employee and team members will be potentially helpful to solve an on-going problem within the boundary of ESM. Otherwise, the employee needs to call for an offline meeting with others to solve the problem. Thus, we expect that employees in the higher level of cognitive absorption use are more likely to achieve higher communication agility.

Another rationale comes from the notion of heightened enjoyment dimension of cognitive absorption [2]. Prior research posited that individuals view enjoyable activities as being less demanding physically and mentally [12]. Therefore, the capacity to handle ongoing communication will be expanded if an employee's level of enjoyment is high because he or she will find contact via ESM less demanding. Thus, those employees in higher cognitive absorption use can deal with a wide range of communication better than who are not. Consistent with the rationale we provided earlier, we expect that the employees have more capability to solve a problem on ESM rather than referring the case to face-to-face settings.

H4. Cognitive absorption use positively affects communication agility.

\subsection{Employee agility and job outcomes}

Innovative behavior refers to an employee's intentional introduction or application of new ideas, products, processes, and procedures to his or her work role, work unit, or organization such as searching out new technologies, suggesting new ways to achieve objectives, applying unique work methods, and investigating and securing resources to implement new ideas [38]. Innovative behavior consists of two primary activities - generation and introduction of new ideas and the realization or implementation of new ideas [38]. Thus, for innovative behavior, it is vital to create new ideas and decide the best move. We expect that employees with high work agility are likely to generate more ideas because they possess a better ability to gather relevant resources to which they can refer. They are also likely to find an appropriate solution since they have access to more information and are better at ruling out inadequate options with the help of internal experts found through ESM.

\section{H5. Work agility positively affects innovative behavior.}

We argue that employees with high communication agility are also likely to possess greater idea generation capability. Those employees are expected to get a better understanding of the need of their working colleagues because they can cover more voices of colleagues available on ESM. Accordingly, they will be more successful in generating ideas because they have a more concrete understanding of the issues needed to be solved. Besides, the process of idea generation is likely to get better as the volume of time invested increases. Employees with high communication agility will have more time to focus on their tasks since they are less suffering from additional offline meetings. Furthermore, we posit that employees with high communication agility will result in better performance in the realization of new ideas. Since their thoughts are likely to be relevant to the need, the choice of an alternative will be made among many pertinent suggestions, increasing the chance of a right choice. Also, again, employees with high communication agility can focus on their tasks for more time than others who are not. Thus, this advantage is likely to lead to better outcomes. Stated formally:

H6. Communication agility positively affects innovative behavior.

\section{Methodology}

\subsection{Data}

To test our hypotheses, we collected two waves of surveys from a large US-based Fortune 500 manufacturing company which engaged in an ESM 
implementation. The company employs approximately 50,000 people worldwide, serving customers in nearly 200 countries. We were given a list of 2,331 prospective users by the ESM implementation team. These employees were from various business units (e.g. corporate communications, information technology, and engineering units) and locations in the US, India, and Europe. Employees were also from various roles within the organization (e.g., specialists, engineers, managers, and directors). We sent surveys to about 1,100 of these employees who just started using this system (two to three months of use). Of these employees, 560 provided completed responses at $\mathrm{T}_{1}\left(51 \%\right.$ response rate). At $\mathrm{T}_{2}$, (approximately five months after $\mathrm{T}_{1}$ ), we sent a followup survey to these 560 employees and received completed responses from 336 employees $(60 \%$ response rate). Among the participants, 58\% were female and the average tenure was six years. About $36 \%$ of participants were between the ages of 31 and $40,42 \%$ between 41 and 60, and $22 \%$ between 25 and 30 . Overall, half of the participants were from the US and half were considered senior engineers or higher.

\subsection{Measurement}

We created measurement items for deep structure use, work agility, and communication agility. To measure deep structure use, we first identified the features of the ESM: Blogs, Wikis, Activities, Forums, Profiles, Media Gallery, Communities, Ideation Blog, Discussion Forums, Files/Document Library, Status Updates, and Bookmarks. Items were created for each aspect of deep structure use (create, view, respond) Participants were asked to assess how frequently they used each feature relative to the use aspect. For example, to measure create, subjects were asked "How frequently do you create/upload/post content using the following features of the ESM at work?".

To measure work agility and communication agility, we reviewed vendor information regarding possible use benefits. Based on the characteristics of each benefit, we matched the benefit to the agility category. Examples of work agility items include: "I am able to find workrelated information faster"; "I am able to reach subject matter experts more quickly than before". Examples of communication agility items include: "I attend fewer conference calls than before"; "I spend less time in meetings than before".

Cognitive absorption use was measured using items from Agarwal and Karahanna [2] and Burton-Jones and Straub [8]. For example, subjects responded to "When using the social media/networking/collaboration tools at work, I feel completely absorbed in what I am doing." Similarly, innovative behavior was measured using items adapted from Parker et al. [28]. For example, subjects indicated the extent of "Suggesting ideas for improvements to director, supervisor, or others". All constructs were measured on a 7-point Likert scale.

We took several steps to ensure and assess the validity of our measures. To garner feedback, first, we met with the ESM implementation team leaders. Second, we piloted the items with about one hundred employees and found acceptable psychometric properties of our measures. Third, with our main data, we assessed convergent and discriminant validities. Overall, factor loadings were greater than 0.73 , and the square roots of AVE were larger than correlation values, suggesting strong convergent and discriminant validity. Last, we conducted Harman's single factor test and found that common method bias was not a serious concern.

\section{Analyses and results}

We tested the structural model using IBM SPSS Amos v.24. Following Baron and Kenny's three steps for mediation analysis, we first estimated the effect of our focal independent variables (ESM use) on the dependent variable (innovative behavior). Second, we investigated whether the path between the independent variables and mediators is significant. Last, we analyzed innovative behavior with both the independent variables and the mediators simultaneously. We controlled for individual differences including age, gender, tenure, prior social media use experience, and innovative behavior at $T_{1}$.

Table 1 presents the results of the effect of ESM use on work and communication agilities. Regarding work agility, we found that the impacts of create and respond are significant at 0.01 with a similar magnitude of coefficients $(0.29$ for create and 0.26 for respond). Cognitive absorption use showed a higher coefficient (0.39), and it was significant at 0.001. However, we did not find a significant effect for view. Thus, $\mathrm{H} 1$ is partially supported, and $\mathrm{H} 2$ is supported.

\begin{tabular}{|l|c|c|}
\hline & \multicolumn{2}{|c|}{ Dependent variables } \\
\cline { 2 - 3 } & $\begin{array}{c}\text { Work } \\
\text { Agility } \boldsymbol{T}_{\mathbf{2}}\end{array}$ & $\begin{array}{c}\text { Communication } \\
\text { agility } \boldsymbol{T}_{\mathbf{2}}\end{array}$ \\
\hline Control variables: & & \\
\hline Age & $\mathrm{ns}$ & $-*$ \\
\hline Gender & $\mathrm{ns}$ & $-*$ \\
\hline Organizational tenure & $*$ & $-*$ \\
\hline Prior use experience & & $* *$ \\
\hline Independent variables: & $.29^{* *}$ & $.25^{* *}$ \\
\hline Deep structure use: create & .08 & $.23^{* *}$ \\
\hline Deep structure use: view & $.26^{* *}$ & .05 \\
\hline Deep structure use: respond & $.39^{* * *}$ & $.40^{* * *}$ \\
\hline Cognitive absorption use & .48 & .41 \\
\hline$R^{2}$ & & \\
\hline
\end{tabular}

Table 1. Predicting influence on agility 
For communication agility, we found significant effects of create and view at 0.01 with a similar magnitude of coefficients $(0.25$ for create and 0.23 for view). Cognitive absorption use was highly significant at 0.001 , and its coefficient was also higher than other effects $(0.40)$. Hence, both $\mathrm{H} 3$ and $\mathrm{H} 4$ are supported.

Table 2 presents the rest of the mediation analysis results. We found that work and communication agility partially mediated the effects of ESM use on innovative behaviors. When we estimated the effect of ESM use and the mediators on innovative behavior simultaneously, we found that work agility is significant at 0.05 with a coefficient of 0.14 . Thus, H5 is supported. Surprisingly, the effect of communication agility on innovative behavior was found to be negative with a coefficient of -0.27 and significant at 0.01 . Thus, H6 is not supported. Besides, the results showed that the effect of create and cognitive absorption use on innovative behavior was significant at 0.05 and 0.001 respectively.

\begin{tabular}{|l|c|c|}
\hline \multirow{2}{*}{ Control variables: } & \multicolumn{2}{|c|}{ Dependent variable } \\
\cline { 2 - 3 } & \multicolumn{2}{|c|}{ Innovative behavior $\boldsymbol{T}_{\mathbf{2}}$} \\
\hline Age & $*$ & $*$ \\
\hline Gender & $-*$ & $\mathrm{~ns}$ \\
\hline Organizational tenure & $*$ & $\mathrm{~ns}$ \\
\hline Prior use experience & $-*$ & $\mathrm{~ns}$ \\
\hline Innovative behavior $\left(T_{1}\right)$ & $62^{* * *}$ & $.59^{* * *}$ \\
\hline Independent Variables: & & \\
\hline Deep structure use: create & $.23^{* *}$ & $.15^{*}$ \\
\hline Deep structure use: view & $-.14^{*}$ & -.10 \\
\hline Deep structure use: respond & .10 & .02 \\
\hline Cognitive absorption use & $.49^{* * *}$ & $.44^{* * *}$ \\
\hline Mediators: & & \\
\hline Work agility & & $.14^{*}$ \\
\hline Communication agility & & $-.27^{* *}$ \\
\hline $\mathrm{R}^{2}$ & .37 & .44 \\
\hline
\end{tabular}

Table 2. Results of influence on job outcomes

\section{Discussion and conclusions}

This study investigated how employees' ESM use changes the way they work highlighting the role of agility at an individual level. We suggest that the superior features of ESM over existing collaboration tools will provide unique opportunities to employees, and thus, they will be agile in work and communication further. In the past, before ESM, organizations had tried to preserve knowledge by almost forcing employees to register their work cases in an internal archive. However, it raised a concern of missing data unless employees ensure their complete participation. It also required a significant managerial effort to motivate employees to do so. Besides, organizations have adopted an expert search module in their enterprise portals to foster experts' knowledge sharing. Despite its helpfulness, a consistent and prompt update of the information on internal experts has been regarded very challenging.

Nevertheless, providing an information-rich environment for employees to find work-related information and a right person who can help them promptly is one of the critical success factors in business today. Moreover, it is crucial to streamlining internal communication process by offering a more efficient interaction channel beyond the communication boundary set by traditional collaboration tools such as emails, instant messengers, and phone calls. In the same manner, $94 \%$ of participants in our focal company thought that collaboration is an important part and even a necessity of their job. We believe that ESM fundamentally changes the way employees work based on our theoretical perspectives provided earlier.

Our results suggest that employees' active engagement on ESM is crucial in improving their work agility. The extent to which employees create a post and respond to others' posts was statistically significant, and their influences were of similar magnitude. Cognitive absorption use showed the highest impact on work agility, and it was highly significant. Surprisingly, the extent to which employees view the available content of ESM was found insufficient to lead higher work agility. The results imply that mere observation of other colleagues' communication and the acquisition of metaknowledge do not guarantee that employees can find work-related resources promptly. Asking a question directly to other colleagues utilizing the broad digitized knowledge reach of ESM is a more efficient way to acquire knowledge on time. Also, it is found that strengthening social relationships with colleagues based on reciprocity is useful to attain expertise when necessary.

Regarding communication agility, the extent to which employees create and view others' posts on ESM was statistically significant, and their impacts were similar. Again, cognitive absorption use showed the highest and significant influence on communication agility. Consistent with our earlier argument, respond was not significant. The results imply that increased common understanding by viewing others' conversations with a timeline, which are uniquely available on ESM, make communications richer and supplement the efficiency problem inherent in online interaction (compared to face-to-face communication) effectively, eliminating any trivial offline meetings having no significant importance. Also, sharing work status and requests for help in an open space are also effective in increasing communication agility by enabling others to grasp the current state. Furthermore, lowered cognitive load through cognitive absorption use expands an employee's capability to deal with a larger 
volume of communications on ESM as well as induce more active engagement resulting in higher productivity in communication.

Surprisingly, contrary to our hypothesis (H6), we found that communication agility has a significant, yet negative, effect on innovative behavior, while work agility is positively relative as we expected. The counter-intuitive result is striking since it suggests an interesting trade-off of employees' ESM use. One possible explanation is communication overload. An employee with high communication agility is expected to have a greater ability to understand colleagues' needs. However, too much consideration of various aspects related to an issue might result in formulating a solution that is not competitive. Given that innovative behavior involves a series of actions generating ideas and ruling out alternatives, an employee with high communication agility is likely to obtain a large volume of information through effective communication in a given time. As a volume of data from different sources increases, more variety of information may exist, which may harm the efficiency of a decision-making process. Another explanation is online communication on ESM is not useful when it comes to tasks requiring creativity. That is, the efficiency of interaction on ESM is insufficient for creative activities due to its lack of non-verbal cues.

This study contributes to theory as followings. First, we examined the effectiveness of employees' ESM use on their primary job outcomes for the first time to our best knowledge. The direct linkage between ESM use and individual job outcomes have not been explored yet despite wide applications of ESM in practice. Second, we conceptualized and operationalized employee-level agility constructs including work agility and communication agility in ESM context. Third, we extended Burton-Jones and Straub [8] by considering the duality of system use, and enriched our understanding of two rich measures of system use. Fourth, we investigated the influence of all proposed constructs empirically with the unique two waves of survey data from a large Fortune 500 company. Last, we introduced innovative behavior as a dependent variable and examined the effects of ESM on it empirically.

We encourage further work on the effects of work agility and communication agility on other job outcomes. As we noted earlier, the negative effect of communication agility was counter-intuitive and may imply the existence of side effects of ESM use. We hope this research will help guide current businesses considering ESM by shedding light on how ESM can benefit their employees. Furthermore, the results of this research will allow companies that have already adopted ESM to streamline and manage employees' ESM use for better performance.

\section{References}

[1] Agarwal, D., van Berkel, A., and Rea, B. 2015. "Simplification of Work: The Coming Revolution": https://dupress.deloitte.com/dup-us-en/focus/humancapital-trends/2015/work-simplification-humancapital-trends-2015.html Retrieved 1 December 2017. [2] Agarwal, R. \& Karahanna, E. 2000. "Time Flies When You're Having Fun: Cognitive Absorption and Beliefs About IT Usage", MISQ (24:4), 665-694.

[3] Alexander, A., Vaughn, P., and Tim, W. 2003. "Motivation and Barriers to Participation in Virtual Knowledge-Sharing Communities of Practice," Journal of Knowledge Management (7:1), 64-77.

[4] Bala, H., Massey, A. P., \& Hsieh, C. J. 2016. "A Multimethod Study of Enterprise Social Media Implementation and Use: Mitigating the Gap between Theory and Practice," Journal of Organizational and End User Computing (JOEUC) (28:3), 141-162.

[5] Bandura, A. 1977. "Self-Efficacy: Toward a Unifying Theory of Behavioral Change," Psychological Review (84:2), 191-215.

[6] Beck, R., Pahlke, I., and Seebach, C. 2014. "Knowledge Exchange and Symbolic Action in Social Media-Enabled Electronic Networks of Practice: A Multilevel Perspective on Knowledge Seekers and Contributors," MISQ (38:4), 1245-1270.

[7] Breu, K., Hemingway, C. J., Strathern, M., and Bridger, D. 2002. "Workforce Agility: The New Employee Strategy for the Knowledge Economy," Journal of Information Technology (17:1), 21-31.

[8] Burton-Jones, A. and Straub, D. W. 2006. "Reconceptualizing System Usage: An Approach and Empirical Test," Information Systems Research (17:3), 228-246.

[9] Chonko, L. B. and Jones, E. 2005. "The Need for Speed: Agility Selling," Journal of Personal Selling \& Sales Management (25:4), 371-382.

[10] Christopher, M. and Towill, D. R. 2000. "Supply Chain Migration from Lean and Functional to Agile and Customised," Supply Chain Management: An International Journal (5:4), 206-213.

[11] Cohen, M. R. and Maunsell, J. H. R. 2009. "Attention Improves Performance Primarily by Reducing Interneuronal Correlations," Nature Neuroscience (12), 1594.

[12] Csikszentmihalyi, M. 2014. "Toward a Psychology of Optimal Experience," in Flow and the Foundations of Positive Psychology: The Collected Works of Mihaly Csikszentmihalyi, M. Csikszentmihalyi (ed.). Dordrecht: Springer Netherlands, 209-226.

[13] Daft, R. L. and Lengel, R. H. 1986. "Organizational Information Requirements, Media Richness and Structural Design," Management Science (32:5), 554-571. 
[14] Dennis, A. R., Fuller, R. M., and Valacich, J. S. 2008. "Media, Tasks, and Communication Processes: A Theory of Media Synchronicity," MISQ (32:3), 575600.

[15] Dennis, A. R. and Kinney, S. T. 1998. "Testing Media Richness Theory in the New Media: The Effects of Cues, Feedback, and Task Equivocality," Information Systems Research (9:3), 256-274.

[16] DeSanctis, G. and Poole, M. S. 1994. "Capturing the Complexity in Advanced Technology Use: Adaptive Structuration Theory," Organization Science (5:2), 121147.

[17] Eurostat. 2016a. "Enterprises Using Social Media, by Purpose of Use and Size Class, Eu-28, 2015" http://ec.europa.eu/eurostat/statistics-

explained/index.php/File:V3 Enterprises using_social media, by purpose of use and size class, EU28,2015 (\%25 of enterprises_using_social_media).p ng Retrieved 2 December 2017.

[18] Eurostat. 2016b. "Enterprises Using Social Media, by Type of Social Media, Eu-28, 2013 and 2015" http://ec.europa.eu/eurostat/statisticsexplained/index.php/File:V3 Enterprises_using_social media, by type of social_media, EU28,2013 and 2015 (\%25 of enterprises).png

Retrieved December 2, 2017.

[19] Fink, L. and Neumann, S. 2007. "Gaining Agility through It Personnel Capabilities: The Mediating Role of It Infrastructure Capabilities," Journal of the Association for Information Systems (8:8), 440.

[20] Gouldner, A. W. 1960. "The Norm of Reciprocity: A Preliminary Statement," American Sociological Review (25:2), 161-178.

[21] Hopp, W. J., Tekin, E., and Oyen, M. P. V. 2004. "Benefits of Skill Chaining in Serial Production Lines with Cross-Trained Workers," Management Science (50:1), 83-98.

[22] Huang, Y., Singh, P. V., and Ghose, A. 2015. "A Structural Model of Employee Behavioral Dynamics in Enterprise Social Media," Management Science (61:12), 2825-2844.

[23] LaBerge, D. and Samuels, S. J. 1974. "Toward a Theory of Automatic Information Processing in Reading," Cognitive Psychology (6:2), 293-323.

[24] Leonardi, P. M. 2014. "Social Media, Knowledge Sharing, and Innovation: Toward a Theory of Communication Visibility," Information Systems Research (25:4), 796-816.

[25] Leonardi, P. M. 2015. "Ambient Awareness and Knowledge Acquisition: Using Social Media to Learn" Who Knows What" and" Who Knows Whom"," MISQ (39:4), 747-762.

[26] Muduli, A. 2013. "Workforce Agility: A Review of Literature," IUP Journal of Management Research (12:3), 55 .
[27] Nahapiet, J. and Ghoshal, S. 1998. "Social Capital, Intellectual Capital, and the Organizational Advantage," Academy of Management Review (23:2), 242-266.

[28] Parker, S. K., Williams, H. M., and Turner, N. 2006. "Modeling the Antecedents of Proactive Behavior at Work," Journal of Applied Psychology (91:3), 636652.

[29] Qin, R. and Nembhard, D. A. 2010. "Workforce Agility for Stochastically Diffused Conditions - a Real Options Perspective," International Journal of Production Economics (125:2), 324-334.

[30] Sambamurthy, V., Bharadwaj, A., and Grover, V. 2003. "Shaping Agility through Digital Options: Reconceptualizing the Role of Information Technology in Contemporary Firms," MISQ (27:2), 237-263.

[31] Siemens, G. 2005. "Connectivism: Learning as Network-Creation," ASTD Learning News (10:1), 1-28. [32] Spreitzer, G. M. 1996. "Social Structural Characteristics of Psychological Empowerment," The Academy of Management Journal (39:2), 483-504.

[33] Tallon, P. P. and Pinsonneault, A. 2011. "Competing Perspectives on the Link between Strategic Information Technology Alignment and Organizational Agility: Insights from a Mediation Model," MISQ (35:2), 463-486.

[34] Towill, D. and Christopher, M. 2002. "The Supply Chain Strategy Conundrum: To Be Lean or Agile or to Be Lean and Agile?," International Journal of Logistics Research and Applications (5:3), 299-309.

[35] Webster, J., Trevino, L. K., and Ryan, L. 1993. "The Dimensionality and Correlates of Flow in HumanComputer Interactions," Computers in Human Behavior (9:4), 411-426.

[36] Weill, P., Subramani, M., and Broadbent, M. 2002. "Building It Infrastructure for Strategic Agility," MIT Sloan Management Review (44:1), 57-65.

[37] Wu, L. 2013. "Social Network Effects on Productivity and Job Security: Evidence from the Adoption of a Social Networking Tool," Information Systems Research (24:1), 30-51.

[38] Yuan, F. and Woodman, R. W. 2010. "Innovative Behavior in the Workplace: The Role of Performance and Image Outcome Expectations," Academy of Management Journal (53:2), 323-342.

[39] Yusuf, Y. Y. and Adeleye, E. O. 2002. "A Comparative Study of Lean and Agile Manufacturing with a Related Survey of Current Practices in the Uk," International Journal of Production Research (40:17), 4545-4562.

[40] Yusuf, Y. Y., Sarhadi, M., and Gunasekaran, A. 1999. "Agile Manufacturing:: The Drivers, Concepts and Attributes," International Journal of Production Economics (62:1), 33-43. 